\title{
INFLUÊNCIA DA LOCALIZAÇÃO DOTUMOR NA EXPRESSÃO TECIDUAL DA PROTEÍNA p53 EM DOENTES COM CÂNCER COLORRETAL. ESTUDO DE 100 CASOS
}

\author{
INFLUENCE OF TUMOR LOCALIZATION ON THE TISSUE EXPRESSION OF P53 \\ PROTEIN IN PATIENTS WITH COLORECTAL CANCER. STUDY OF 100 CASES
}

\author{
Carlos Augusto Real Martinez TCBC-SP'; Denise Gonçalves Priolli TCBC-SP²; \\ Izilda Aparecida Cardinalli ${ }^{3}$; José Aires Pereira ${ }^{4}$; Adriana Valim Portes ${ }^{5}$; \\ Nelson Fontana Margarido TCBC-SP 6
}

\begin{abstract}
RESUMO: Objetivo: O objetivo do presente estudo foi verificar, se existem diferenças na expressão tecidual da proteína p53 segundo a localização do tumor em doentes com câncer colorretal. Método: Foram estudados 100 doentes (54 mulheres), com média de idade de 59,8 anos com adenocarcinoma colorretal. A expressão da proteína p53 foi analisada por imunoistoquímica, com anticorpo monoclonal anti-p53 pela técnica da estreptavidina-biotina-peroxidase. A expressão tecidual da proteína p53 foi relacionada às variáveis: gênero, idade, grau histológico, tipo histológico, tamanho do tumor, estadiamento TNM, profundidade de invasão da parede intestinal, comprometimento linfonodal, invasão angiolinfática, localização do tumor no intestino grosso em relação à flexura esplênica. Na avaliação estatística da relação entre expressão da proteína p53 e as variáveis consideradas empregouse o teste qui-quadrado, estabelecendo-se nível de significância de 5\% ( $<<0,05)$. Resultados: A proteína p53 foi positiva em $77 \%$ dos casos. Com relação as diferentes variáveis consideradas verificou-se maior tendência de expressão da proteína mutante quando se considerava a idade $(\mathrm{p}=0,001)$, grau histológico $(\mathrm{p}=0,001)$, tipo histológico $(\mathrm{p}=0,001)$, estádios tardios da classificação TNM $(\mathrm{p}=0,001)$, maior profundidade de invasão na parede cólica $(\mathrm{p}=0,001)$, comprometimento linfonodal $(\mathrm{p}=0,001)$, invasão angiolinfática $(\mathrm{p}=0,02)$, localização após a flexura esplênica $(\mathrm{p}=0,001)$, não se encontrando relação com gênero $(\mathrm{p}=0,49)$ e tamanho do tumor $(\mathrm{p}=0,08)$. Conclusão: Os resultados do presente estudo permitem concluir que a expressão da proteína p53 mutante ocorre com maior freqüência nos tumores localizados a partir da flexura esplênica (Rev. Col. Bras. Cir. 2008; 35(4): 235-243).
\end{abstract}

Descritores: Neoplasias do colo; Marcadores biológicos de tumor; Proteína supressora de tumor p53; Genes p53; Imunoistoquímica.

\section{INTRODUÇÃO}

No Brasil o câncer colorretal (CCR) ocupa o quarto lugar como causa mais comum de morte relacionada a neoplasias malignas e sua incidência vem aumentando em comparação a outros tipos de tumores que acometem o aparelho digestivo ${ }^{1}$. A doença incide com maior freqüência entre a $5^{\text {a }}$ e $7^{\text {a }}$ décadas de vida acometendo dois a seis por cento da população mais jovem ${ }^{1,2}$. Com o aumento da expectativa de vida o CCR apresenta importância crescente no perfil da mortalidade por câncer estimando-se em $6 \%$ o risco acumulado de desenvolvimento da enfermidade ao longo da vida ${ }^{3}$.

A partir do início da década de oitenta vem ocorrendo aumento progressivo na incidência de tumores localizados no cólon direito e decréscimo nos localizados no reto ${ }^{4}$. Estima-se que entre as décadas de setenta e noventa, houve aumento em cerca de $10 \%$ na incidência de tumores localizados no cólon proximal (CP), particularmente nos enfermos mais idosos ${ }^{4-6}$. Os motivos desta progressiva mudança na distribuição do CCR quando se comparam tumores localizados antes e após a flexura esplênica ainda são objetos de estudo acreditando-se que possam estar relacionados a mecanismos carcinogênicos distintos ${ }^{7,8}$.

Os cólons proximal e distal possuem diferentes origens embriológicas ${ }^{8,9}$. Enquanto o ceco, cólon ascendente, e os dois terços proximais do cólon transverso originam-se a partir do intestino médio, a flexura esquerda, o cólon descendente, sigmóide e o reto originam-se do intestino posterior ${ }^{7,8}$. Estas origens embriológicas distintas encontram-se refletidas nos diferentes aspectos anatômicos quando se considera o suprimento sangüíneo arterial, drenagem venosa, linfática e inervação de cada um dos segmentos do cólon e reto. Da

\footnotetext{
1. Professor Adjunto Doutor do Programa de Pós-Graduação em Ciências da Saúde da USF; Chefe do Serviço de Cirurgia Geral do Hospital Universitário São Francisco, Bragança Paulista, São Paulo - SP.

2. Professor Adjunto Doutor do Programa de Pós-Graduação em Ciências da Saúde da USF.

3. Professor Assistente Doutor da Disciplina de Anatomia Patológica da USF, Bragança Paulista, São Paulo - SP

4. Professor Assistente Mestre da Disciplina de Anatomia Patológica da USF, Bragança Paulista, São Paulo - SP.

5. Acadêmica do $6^{\circ}$ ano do Curso de Medicina da USF, Bragança Paulista, São Paulo - SP.

6. Professor Livre Docente do Departamento de Cirurgia da Universidade de São Paulo, São Paulo - SP.
}

Recebido em 28/12/2007

Aceito para publicação em 04/04/2008

Conflito de interesses: nenhum

Fonte de financiamento: nenhuma

Trabalho realizado pelo Programa de Pós-graduação em Ciências da Saúde da Universidade São Francisco (USF), Bragança Paulista, São Paulo. Trabalho contemplado com o Prêmio de Melhor Pôster apresentado durante o $I^{\circ}$ Congresso Paulista de Cirurgia (XV Assembléia Cirúrgica de São Paulo - CBC-SP e VI Congresso da SOBRACIL-SP- 2006). 
mesma forma, as funções fisiológicas, metabólicas no epitélio de cada segmento colorretal também diferem sugerindo que na realidade o intestino grosso seja constituído de dois órgãos distintos dispostos em continuidade ${ }^{7,9,10}$. Estudos genéticos recentes utilizando técnicas de "microarray" demonstraram que o perfil de expressão de genes que controlam o ciclo proliferativo das células da mucosa do cólon é diferente quando se comparam o $\mathrm{CP}$ e o cólon distal (CD), sugerindo que existam mecanismos distintos de respostas destes genes a ação de agentes carcinogênicos intraluminais ${ }^{11}$. Tais evidências corroboram a idéia de que existem diferentes vias de carcinogênese envolvidas no desenvolvimento do $\mathrm{CCR}^{9,10,12}$.

O modelo clássico da carcinogênese do CCR encontra-se baseado na seqüência adenoma-carcinoma no qual o surgimento do tumor ocorre a partir de um processo seqüencial e progressivo que envolve a ativação de oncogenes (K-ras) e a inativação de genes supressores de tumor (APC, DCC, p53) ${ }^{13,14}$. Este modelo de carcinogênese, onde existe instabilidade cromossômica, é habitualmente encontrado na maioria dos tumores localizados nos segmentos distais do cólon e no reto $^{14}$. Todavia, evidenciou-se que mais de $45 \%$ dos tumores localizados no CP, se originam a partir de epitélio sem pólipos pré-existentes, sendo por isso considerados câncer de novo ${ }^{15}$. Neste modelo de carcinogênese, que atinge 10 a $15 \%$ dos casos de CCR esporádico, ao invés de existir instabilidade cromossômica haveria instabilidade genômica por mutações nas proteínas de reparo do DNA, fenômeno conhecido como instabilidade de microsatélites (IMS) ${ }^{16}$. Esta via distinta da carcinogênese colorretal é substanciada ao se constatar que tumores associados à instabilidade de microsatélites, de forma diferente dos tumores decorrentes de instabilidade cromossômica, localizam-se com maior freqüência no CP, apresentam aspectos histopatológicos característicos, tais como serem diplóides, crescimento exofítico, pior grau histológico, maior tendência à produção de muco, menor índice de mutações no gene p53 e, paradoxalmente, encontram-se associados a melhor prognóstico ${ }^{16}$.

O gene p53 é um gene supressor de tumor localizado no cromossomo 17, sendo responsável pela transcrição de proteína com peso molecular de $53 \mathrm{kD}$ que possui importante papel no controle do ciclo celular. Mutações neste gene é fenômeno comum na carcinogênese humana sendo encontrada em 60 a $80 \%$ dos tumores colorretais ${ }^{17-19}$.

Ao se considerar os diferentes mecanismos de carcinogênese, bem como os diversos aspectos epidemiológicos envolvidos no CCR, existem dúvidas quanto a maior ou menor frequiência de mutações no gene p53, e conseqüentemente na proteína por ele transcrita, quando se comparam tumores localizados antes e após a flexura esplênica. O conhecimento destas diferenças pode se tornar importante na melhor compreensão de aspectos anátomo-patológicos do tumor, seleção de pacientes para tratamento adjuvante, resposta à radioterapia e quimioterapia e, sobretudo, da evolução clinica da doença ${ }^{17,19-23}$.

O objetivo do presente estudo foi avaliar a existência de diferenças na expressão tecidual da proteína p53 quando se comparam tumores localizados nos CP e CD, correlacionando-a as principais variáveis clínicas e histopatológicas.

\section{MÉTODO}

A realização deste trabalho foi aprovada pelo Comitê de Ética em Pesquisa da Universidade São Francisco (Parecer CEP/CBS 56/05 de 28/04/2005) tendo todos os pacientes, após esclarecimento dos objetivos da pesquisa, assinado Termo de Consentimento Livre e Esclarecido concordando em participar espontaneamente do estudo.

Foram estudados os espécimes cirúrgicos, incluídos em blocos de parafina, de 100 doentes (54 mulheres), com média de idade de 59,8 anos portadores adenocarcinoma colorretal, submetidos a tratamento cirúrgico pela mesma equipe, no período compreendido entre julho de 2000 e julho de 2006. Foram excluídos da pesquisa os menores de 18 anos, portadores de polipose adenomatosa familial (PAF), os suspeitos de pertencerem a famílias com câncer colorretal hereditário não polipose (HNPCC), assim com os portadores de neoplasia extra-intestinal concomitante. Utilizou-se o estadiamento TNM do CCR segundo a UICC (International Union Against Cancer).

Para a realização do estudo histopatológico, todos os espécimes cirúrgicos, previamente fixados em solução de formol a 10\%, foram emblocados em parafina. Três cortes de $4 \mathrm{~mm}$ na periferia do tumor, para obtenção de áreas com e sem neoplasia, foram obtidos de cada bloco, sendo corados, inicialmente, pela técnica da hematoxilina-eosina para diagnóstico anátomo-patológico e avaliação do nível de invasão na parede cólica, variante histológica, grau de diferenciação celular, invasão angiolinfática e comprometimento linfonodal.

Os espécimes emblocados foram submetidos a três cortes adicionais de $4 \mathrm{~mm}$ também retirados da periferia do tumor. As lâminas montadas foram desparafinadas por três banhos sucessivos de cinco minutos em xilol, reidratadas em álcool absoluto, 95\%, $80 \%$ e 50\% seguidas de lavagem em água corrente e destilada. As lâminas foram submersas em solução tampão fosfato de sódio 0,05 M e pH 7,2 (PBS), por 10 minutos e secas com papel filtro. Realizou-se bloqueio das peroxidases endógenas com peróxido de hidrogênio $30 \mathrm{~V}$ a $3 \%$, em câmara úmida, à temperatura ambiente, durante $10 \mathrm{mi}-$ nutos, seguido de mais uma lavagem com PBS por 10 minutos. Realizou-se a recuperação antigênica com solução de citrato 10 mM, pH 6,0 em microondas (potência alta) durante 15 minutos (três ciclos de cinco minutos cada, completando o recipiente com solução de citrato ao término de cada ciclo) e, ao fim desse processo as lâminas foram resfriadas e realizada nova lavagem com $\mathrm{PBS}$ por cinco minutos. $\mathrm{O}$ anticorpo primário monoclonal anti-p53 (Dako Cytomation ${ }^{\circledR}$ Copenhagen. Monoclonal Mouse Anti-human p53 protein. Clone D0-7.) foi diluído na proporção de 1:800 em soro albumina bovina (Sigma®, Saint Louis, EUA). Todas as lâminas foram cobertas com cerca de $100 \mathrm{~mL}$ dessa solução, mantidas por 30 minutos à temperatura ambiente e levadas para câmara úmida em refrigeração a $4^{\circ} \mathrm{C}$ por 24 horas. Após esse período, foram novamente lavadas com PBS por cinco minutos, gotejadas com o anticorpo secundário (Dako Cytomation $\AA$, Copenhagen. Biotinylated Suine anti-goat, mouse-rabbit immunoglobulins), na diluição de 1:160 em PBS, e reservadas em câmara úmida durante uma hora à temperatura ambiente. A seguir, realizou- 
se nova lavagem com PBS e aplicou-se o complexo estreptavidina-biotina-peroxidase (Dako Cytomation ${ }^{\circledR}$, Copenhagen, Dinamarca Strept ABC Complex/HRP) preparado no momento de sua utilização, na diluição de 1:100 em PBS, por 45 minutos. As lâminas foram reveladas, após nova lavagem com PBS, usando-se cromógeno tetrahidrocloridrato de diaminobenzidina (DAB) $10 \mathrm{mg}$ em $10 \mathrm{ml}$ de PBS $+3 \mathrm{~mL}$ de água oxigenada, preparado cinco minutos antes de terminar o tempo de exposição ao complexo ABC, gotejado e permanecendo sobre elas por três minutos. Completado este tempo, foram lavadas em água corrente destilada, contra-coradas com hematoxilina de Harris por 45 segundos, e novamente lavadas em água corrente destilada para, em seguida, serem desidratadas, por submersão em concentrações crescentes de etanol e em xilol, duas vezes por minuto cada. Finalmente, foram rotuladas, montadas, fotografadas e analisadas após 24 horas. O controle negativo da técnica foi realizado pela execução da técnica sem a adição do anticorpo primário enquanto o positivo a partir de lâmina proveniente de enfermo portador de reconhecida expressão positiva.

Para análise imunoistoquímica utilizou-se microscópio óptico comum, com magnificação final de 200x. Considerou-se como reação positiva à coloração nuclear que ocorreu de modo difuso, com pontos de intensidade variáveis e distribuição homogênea. Todas as lâminas foram lidas por dois patologistas experientes, sem conhecimento prévio das características clínicas de cada doente e com acesso somente aos seus próprios resultados, os quais classificaram a expressão tecidual da proteína p53 segundo sua positividade ou não. Após leitura de três campos adotou-se como valor individual para cada patologista o resultado modal da leitura e como valor final, a média da leitura dos dois profissionais. Valores conflitantes foram analisados conjuntamente até existir consenso. Considerou-se ausência de expressão tecidual quando menos de $10 \%$ das células analisadas apresentavam expressão tecidual para a proteína p53 (Figura 1).

A leitura da imunocoloração foi sempre realizada na região de graduação (diferenciação) histológica do tumor definida previamente no estudo convencional pela técnica da hematoxilina-eosina. Assim, caso a neoplasia fosse considerada como bem diferenciada a leitura era realizada em área bem diferenciada.

\section{Análise estatística}

Os dados obtidos com relação à tendência de expressão tecidual da proteína p53 segundo as diferentes variáveis consideradas foram estudados pelo teste do qui-quadrado adotando-se nível de significância de $5 \%(\mathrm{p}<0,05)$. Para análise estatística empregou-se o programa SPSS 13.0Ò (SPSS Inc., Chicago, Illinois-USA) para Windows.

\section{RESULTADOS}

Dos 100 doentes estudados $77 \%$ apresentaram expressão tecidual da proteína p53 mutante. A tabela 1 mostra as características clínicas e histopatológicas da casuística estudada.

A tabela 2 mostra os resultados da expressão da proteína p53 com relação as variáveis clínicas e histopatológicas estudadas.

\section{DISCUSSÃO}

Há mais de uma década Fearon e Vogelstein propuseram, pela primeira vez, um modelo seqüencial de alterações genéticas responsáveis pelo desenvolvimento do $\mathrm{CCR}^{14}$. Este artigo causou enorme impacto na melhor compreensão nas bases moleculares da formação do CCR. Na mesma época, outro artigo, despertou atenção quando propôs a existência de duas categorias de CCR de acordo com a localização do tumor nos segmentos proximal ou distal do intestino grosso ${ }^{8}$. Até então o CCR era habitualmente subdividido segundo sua localização em dois grandes grupos: câncer do cólon e do reto. Do ponto de vista cirúrgico esta subdivisão é feita em bases puramente anatômicas segundo o tumor situar-se na cavidade abdominal ou na pelve. Essa maneira de subdividir o CCR apresenta importância clínica com relação à indicação do tratamento complementar, uma vez que a radioterapia somente
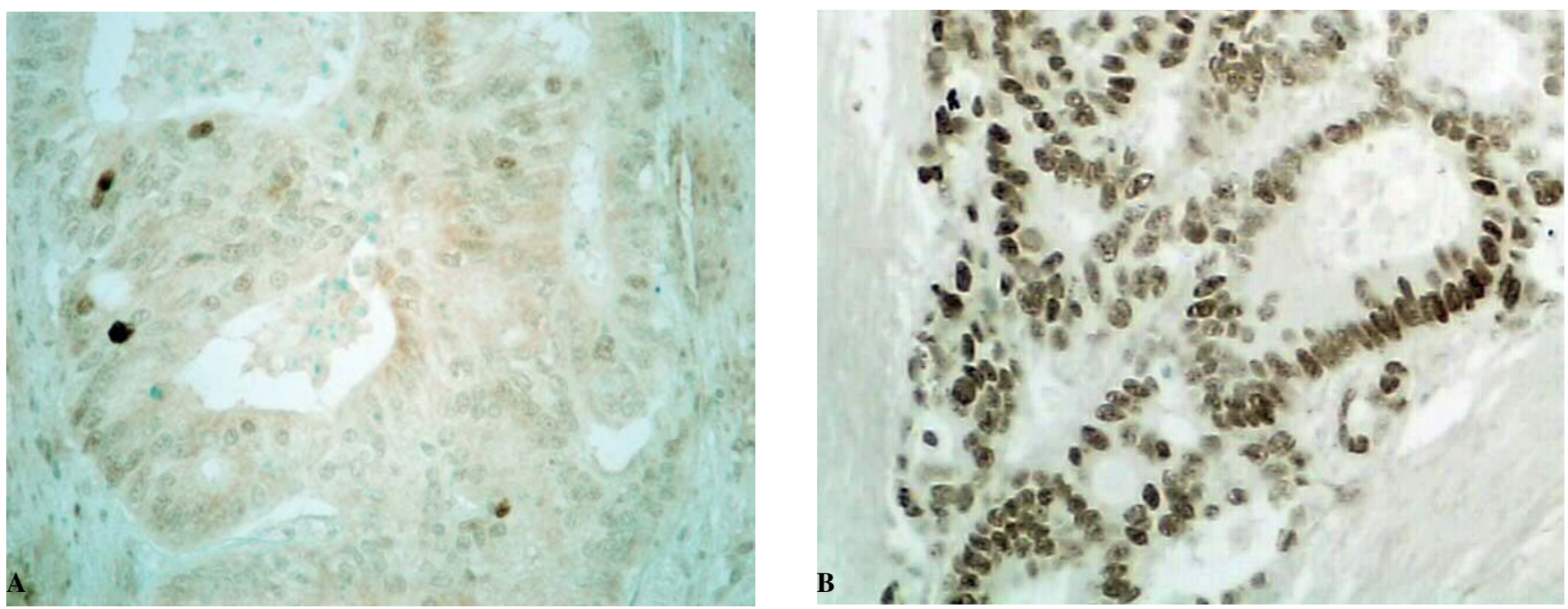

Figura 1-A - Carcinoma colorretal com expressão tecidual negativa para proteína p53 (I.H. 200x. B - Carcinoma colorretal com expressão tecidual positiva para proteína p53 (I.H. 200x). 
Tabela 1 - Características anátomo-clinicas da casuística estudada.

\begin{tabular}{|c|c|}
\hline Variáveis & $\mathrm{N}^{0}$ de $\operatorname{casos}(\%)$ \\
\hline \multicolumn{2}{|l|}{ Sexo } \\
\hline Homem & $46(46)$ \\
\hline Mulher & $54(54)$ \\
\hline \multicolumn{2}{|l|}{ Idade } \\
\hline$<70$ anos & $78(78)$ \\
\hline$>70$ anos & $22(22)$ \\
\hline \multicolumn{2}{|l|}{ Topografia } \\
\hline Cólon Proximal & $26(26)$ \\
\hline Cólon Distal & 74 (74) \\
\hline \multicolumn{2}{|c|}{ Grau Histológico (diferenciação) } \\
\hline Bem & $33(33)$ \\
\hline Moderadamente & $63(63)$ \\
\hline Pouco & 4 (4) \\
\hline \multicolumn{2}{|l|}{ Tipo histológico } \\
\hline Intestinal & $81(81)$ \\
\hline Mucinoso & 19 (19) \\
\hline \multicolumn{2}{|l|}{ Classificação TNM } \\
\hline 0 & 4 (4) \\
\hline I & $21(21)$ \\
\hline II & $45(45)$ \\
\hline III & $23(23)$ \\
\hline IV & $7 \quad(7)$ \\
\hline \multicolumn{2}{|c|}{ Infiltração da parede Cólica (T) } \\
\hline $\mathrm{T}_{\mathrm{is}-2}$ & $26(26)$ \\
\hline $\mathrm{T}_{3-4}^{1-2}$ & $74(74)$ \\
\hline \multicolumn{2}{|l|}{ Linfonodos $(\mathbf{N})$} \\
\hline $\mathrm{N}_{0}$ & $72(72)$ \\
\hline $\mathrm{N}_{1-2}$ & $28(28)$ \\
\hline \multicolumn{2}{|l|}{ Tamanho do tumor } \\
\hline$<5,0 \mathrm{~cm}$ & $56(56)$ \\
\hline$>5,1 \mathrm{~cm}$ & 44 (44) \\
\hline \multicolumn{2}{|c|}{ Invasão angiolinfática } \\
\hline Presente & $40(40)$ \\
\hline Ausente & $60(60)$ \\
\hline \multicolumn{2}{|c|}{ Localização do tumor no cólon } \\
\hline Reto & $35(35)$ \\
\hline Sigmóide & $31(31)$ \\
\hline Descendente & $8 \quad(8)$ \\
\hline Transverso & 3 (3) \\
\hline Ascendente & $23(23)$ \\
\hline
\end{tabular}

é indicada em tumores mais avançados, localizados principalmente no reto médio e distal. Assim, tumores situados no cólon independente da sua topografia, passam a ser considerados como grupo homogêneo com proposta terapêutica adjuvante semelhante ${ }^{24}$.

Todavia, há várias décadas vêm sendo demonstradas diferenças na epidemiologia, comportamento clínico e aspectos histopatológicos, quando se comparam tumores localizados antes e após a flexura esplênica..$^{7-10,12,25,26}$. Os recentes avanços da biologia molecular na compreensão carcinogênese do CCR vêm confirmando estas diferenças, mostrando que tumores localizados no $\mathrm{CP}$ representam entidade distinta com características clínicas e patológicas diferentes dos localizados no $\mathrm{CD}^{7-11}$.

O conceito que o intestino grosso é composto por dois órgãos distintos dispostos em continuidade não é novo para embriologistas, anatomistas e fisiologistas, existindo inúmeras evidências que reforçam esta afirmativa ${ }^{10}$. Os $\mathrm{CP}$ e distal possuem origens embriológicas distintas confirmadas pelas diferenças anatômicas existentes entre eles ${ }^{8-10,24}$. O ceco, cólon ascendente e os dois terços proximais do cólon transverso originam-se a partir do intestino médio, enquanto a flexura esplênica, o cólon descendente, sigmóide e o reto a partir do intestino posterior ${ }^{7-10,12,24,25}$. Existem diferenças no suprimento sangüíneo arterial pois, enquanto o $\mathrm{CP}$ é suprido a partir de ramos oriundos da artéria mesentérica superior, o CD é suprido a partir da artéria mesentérica inferior ${ }^{7,24}$. Enquanto a drenagem venosa do CP se dá para a veia mesentérica superior, o $\mathrm{CD}$ drena para veia mesentérica inferior ${ }^{8}$. A rede linfática obedece o mesmo padrão de distribuição. A inervação também ocorre a partir de regiões anatômicas distintas, pois enquanto o CP é inervado a partir de fibras vagais, o $\mathrm{CD}$ e reto de fibras nervosas oriundas do plexo sacral ${ }^{7-9}$. Histológicamente também ocorrem diferenças ${ }^{8-10}$. O comprimento das criptas cólicas é maior no CP, assim como a rede capilar submucosa é mais exuberante, fato este relacionado a maior capacidade de absorção de água e eletrólitos pelo $\mathrm{CP}^{7,9}$. $\mathrm{O}$ índice de apoptose celular decresce progressivamente no sentido proximal-distal, provavelmente em conseqüência a diferentes expressões de genes controladores do ciclo celular ${ }^{24}$.

Do ponto de vista fisiológico, o cólon apresenta importância no mecanismo de regulação da absorção de água, sódio e cloretos e excreção de potássio e bicarbonatos. A principal enzima envolvida no processo de troca de ânions é a anidrase carbônica que possui altas concentrações no $\mathrm{CP}$, e baixa no CD sugerindo que o CP tenha maior importância nos mecanismos de troca hidroeletrolítica. ${ }^{10}$ A desconjugação dos sais biliares é realizada de maneira decrescente a partir do CP e, em virtude da maior concentração de sais biliares no $\mathrm{CP}$, vem sendo proposto que alterações do metabolismo dos sais biliares possam estar relacionadas ao maior risco do desenvolvimento de tumores do CP. ${ }^{9,10}$ Reforçam estas suposições estudos epidemiológicos demonstrando que a colecistectomia pode ser considerada como fator de risco no desenvolvimento de câncer do $\mathrm{CP}$, mas não no $\mathrm{CD}^{27,28}$.

Quando se comparam os aspectos histopatológicos dos tumores localizados no CP e CD também se observam características diferentes. Neoplasias do CP geralmente possuem crescimento exofítico, mais comumente são produtoras de muco, diplóides e menos associadas à presença de pólipos ${ }^{10}$. Em contrapartida, tumores do CD possuem padrão de crescimento úlcero-infiltrativo, mais raramente são produtores de muco, aneuplóides e encontram-se freqüentemente associados a pólipos intestinais ${ }^{10}$.

Recentemente, com o advento das técnicas de "microarray", que permitem o estudo simultâneo da expressão de vários genes obtidos de uma mesma amostra de tecido, verificou-se que o perfil de expressão de mais de 1000 genes que controlam o ciclo celular das células da mucosa do cólon são diferentes nos $\mathrm{CP}$ e distal ${ }^{11}$. A expressão de alguns deles 
Tabela 2 - Relação entre expressão tecidual da proteína p53 e as demais variáveis clínicas e histopatológicas.

\begin{tabular}{|c|c|c|c|c|}
\hline & $\mathrm{N}^{0}$ de casos & p53 positiva $(\%)$ & p53 negativa $(\%)$ & Valor de $p$ \\
\hline \multicolumn{5}{|l|}{ Sexo } \\
\hline Homem & 46 & $38 \quad(82,6)$ & $8(17,4)$ & \multirow[t]{2}{*}{0,936} \\
\hline Mulher & 54 & $39 \quad(72,2)$ & $15(27,8)$ & \\
\hline \multicolumn{5}{|l|}{ Idade } \\
\hline$£ 70$ anos & 78 & $61 \quad(78,2)$ & $17(21,8)$ & \multirow[t]{2}{*}{0,001} \\
\hline$>70$ anos & 22 & $16(72,7)$ & $6(27,3)$ & \\
\hline \multicolumn{5}{|c|}{ Grau Histológico (diferenciação) } \\
\hline Bem & 33 & $22(66,6)$ & $11(33,4)$ & \multirow[t]{3}{*}{0,04} \\
\hline Moderadamente & 63 & $51 \quad(80,9)$ & $11(19,1)$ & \\
\hline Pouco & 4 & $4(100)$ & 0 & \\
\hline \multicolumn{5}{|l|}{ Tipo histológico } \\
\hline Intestinal & 81 & $63(77,8)$ & $18(22,2)$ & \multirow[t]{2}{*}{0,001} \\
\hline Mucinoso & 19 & $15 \quad(78,9)$ & $4(21,1)$ & \\
\hline \multicolumn{5}{|l|}{ Tamanhodo tumor } \\
\hline$£ 5,5 \mathrm{~cm}$ & 56 & $44 \quad(78,5)$ & $14(21,5)$ & \multirow[t]{2}{*}{0,09} \\
\hline$>5,5 \mathrm{~cm}$ & 44 & $33(75,0)$ & $11(25,0)$ & \\
\hline \multicolumn{5}{|l|}{ Estádios (TNM) } \\
\hline 0, I, II & 70 & $55 \quad(78,5)$ & $15(21,5)$ & \multirow[t]{2}{*}{0,001} \\
\hline III, IV & 30 & $22 \quad(73,3)$ & $8(26,7)$ & \\
\hline \multicolumn{5}{|c|}{ Infiltração da parede Cólica (T) } \\
\hline $\mathrm{T}_{1-2}$ & 26 & $18 \quad(75,6)$ & $10(24,4)$ & \multirow[t]{2}{*}{0,001} \\
\hline $\mathrm{T}_{34}^{1-2}$ & 74 & $59 \quad(79,7)$ & $15(20,3)$ & \\
\hline \multicolumn{5}{|l|}{ Linfonodos (N) } \\
\hline $\mathrm{N}_{0}$ & 72 & $56(77,7)$ & $16(22,3)$ & \multirow[t]{2}{*}{0,001} \\
\hline $\mathrm{N}_{12}$ & 28 & $21(75,0)$ & $7(25,0)$ & \\
\hline \multicolumn{5}{|c|}{ Invasão angiolinfática } \\
\hline Presente & 40 & $32(80,0)$ & $8(20,0)$ & \multirow[t]{2}{*}{0,04} \\
\hline Ausente & 60 & $45 \quad(75,0)$ & $15(25,0)$ & \\
\hline \multicolumn{5}{|c|}{ Local do tumor no cólon } \\
\hline Reto & 35 & $29 \quad(82,8)$ & $6(17,2)$ & \multirow[t]{5}{*}{0,04} \\
\hline Sigmóide & 31 & $25(80,6)$ & $6(19,4)$ & \\
\hline Descendente & 8 & $5(62,5)$ & $3(37,5)$ & \\
\hline Transverso & 3 & $2(66,7)$ & $1(33,3)$ & \\
\hline Ascendente & 23 & $16 \quad(69,5)$ & $7(30,5)$ & \\
\hline \multicolumn{5}{|l|}{ Localização } \\
\hline Cólon Proximal & 26 & $18 \quad(69,2)$ & $8(30,8)$ & \multirow[t]{2}{*}{0,001} \\
\hline Cólon Distal & 74 & $59 \quad(79,7)$ & $15(20,3)$ & \\
\hline
\end{tabular}

pode ser até três vezes mais intensa dependendo do segmento considerado ${ }^{11}$. Estes achados sugerem que existem mecanismos distintos de respostas destes genes à ação de agentes carcinogênicos, promovendo de modo diferente, nos segmentos proximal e distal, o silenciamento de genes supressores de tumores e ativação de oncogenes ${ }^{11}$. É possível que estas diferenças relacionem-se a diferentes aspectos histopatológicos encontrados nos tumores dos dois segmentos intestinais, corroborando a idéia que existem diferentes vias de carcinogênese envolvidas no desenvolvimento do $\mathrm{CCR}^{9,10,12,15}$.

Durante anos acreditou-se que a maioria, senão todos, os tumores colorretais malignos desenvolviam-se a partir de pólipos adenomatosos pré-existentes ${ }^{7,8}$. Esta possibilidade baseava-se na teoria da seqüência adenoma-carcinoma onde o processo de desenvolvimento do CCR ocorria a partir de adenomas pré-existentes, existindo uma seqüência progressiva de mutações, silenciando genes supressores de tumores (APC, p53, DCC) e ativando oncogenes (ki-ras) ${ }^{14}$. Contudo, demonstrou-se mais tarde a existência de um tipo peculiar de CCR, geralmente localizado no $\mathrm{CP}$, que se originava "de novo" a partir da mucosa cólica onde não existia anteriormente uma lesão polipóide propriamente dita ${ }^{15,16}$. Estudos genéticos demonstraram que, neste tipo de tumor, mutações dos genes p-53 e k-ras são menos freqüentes, sugerindo uma via de carcinogênese diferente da clássica seqüência adenomacarcinoma $^{12,20}$. Este tipo peculiar de CCR esporádico, localizado antes da flexura esplênica, apresenta alterações histopatológicas e moleculares semelhantes ao tumores de doentes com HNPCC, onde as neoplasias possuem padrão de crescimento exofítico, maior tendência à produção de muco, 
pior grau histológico, menor comprometimento linfonodal e, paradoxalmente, evolução mais favorável quando comparado aos tumores localizados após a flexura esplênica ${ }^{7-12}$. Estudos avaliando a presença de IMS e mutações da proteína p53, comparando tumores localizados nos $\mathrm{CP}$ e $\mathrm{CD}$, demonstraram que os mecanismos moleculares da carcinogênese são diferentes quando se considera a localização da neoplasia ${ }^{22}$.

A p53 é uma proteína de 53Kda codificada por gene situado no cromossomo 17, de mesmo nome. Sua função encontra-se relacionada à preservação da integridade do código genético, mantendo a mesma seqüência de nucleotídeos ao longo de toda a cadeia de DNA presente em cada célula do organismo ${ }^{29}$. A proteína normal (wild type), durante a divisão celular na fase $\mathrm{G} 2$ da mitose, verifica a eventual presença de mutações decorrentes de erros de replicação do DNA. Caso exista algum erro na sequiência de nucleotídeos a proteína normal interrompe o processo de divisão celular e, partir deste ponto, dois caminhos distintos podem ser seguidos: a correção do erro de replicação pelas das proteínas de reparo ou, quando isso não é possível, indução da apoptose impedindo que uma mutação possa ser transmitida a gerações de células futuras $^{29}$. A forma selvagem da proteína p53 tem vida média muito curta, e sua rápida degradação pela célula, torna difícil a detecção por imunoistoquímica. De outro modo, a proteína mutante, pela maior estabilidade molecular, apresenta maior tempo de degradação, o que possibilita sua identificação tecidual, permitindo sua utilização como marcador indireto da mutação do gene p53 $3^{29}$.

As mutações da proteína p53 não ocorrem em todos os casos de CCR. É possível que o estudo destas mutações permitam uma melhor compreensão dos distúrbios biomoleculares no $\mathrm{CCR}^{30}$. Recentemente, um levantamento da literatura, avaliando nove estudos, verificou que sete deles relacionavam mutações da proteína 533 como marcador de pior prognóstico nos portadores de $\mathrm{CCR}^{10}$. Khalemberg et al. encontraram sobrevida de quatro anos em $71 \%$ dos enfermos com proteína normal e somente de $54 \%$ nos que apresentavam mutações ${ }^{31}$.

A incidência de mutações na proteína p53 não ocorre com a mesma freqüência quando se comparam tumores localizados antes e após a flexura esplênica ${ }^{20}$. Estudos vêm demonstrando que mutações do gene p53 geralmente são 1,5 a 3 vezes mais freqüentes nos tumores originados no $\mathrm{CD}^{18}$. Revisão da literatura considerando 13 artigos que analisaram mutações da proteína p53, comparando tumores localizados nos $\mathrm{CP}$ e $\mathrm{CD}$, verificou índices médios de mutações maiores (37\% e $52 \%$, respectivamente) nos tumores do $\mathrm{CD}^{18}$.

Os resultados do presente estudo parecem corroborar estes achados quando se verificou que em 69,2\% (18/26) dos tumores do CP havia expressão tecidual da proteína p53 mutante, enquanto nas neoplasias localizadas no CD mutações ocorriam em 79,7\% (59/74) dos casos (p=0,001). É possível que a maior incidência de positividade nos tumores localizados no CP em comparação a literatura, possa ser imputada ao método imunoistoquímico utilizado e aos critérios de positividade adotados. Quando se comparou somente tumores situados no CD (descendente, sigmóide e reto), verificouse maior tendência a mutações na proteína, quanto mais caudal fosse à localização da neoplasia. Constatou-se que 82,8\%
(29/35) dos tumores localizados no reto apresentavam mutações, e aqueles localizados nos cólons sigmóide e descendente, $80,6 \%$ (25/31) e 62,5\% (5/8), respectivamente.

Não houve diferença significante na expressão tecidual da proteína p53 quando se considerou o gênero, achados semelhante aos da literatura ${ }^{18}$. Analisando apenas tumores localizados no $\mathrm{CD}$, comparando homens e mulheres, verificou-se a presença da proteína mutante nos homens em $88 \%$ (31/35) e em 71\% (28/39) das mulheres, demonstrando tendência a mutações em homens com tumores de localização distal. Nos tumores localizados no CP, comparando homens e mulheres, encontraram-se mutações em $63 \%$ (7/11) e 73,3\% (11/15), respectivamente, demonstrando tendência a mutações nas mulheres com tumores de localização proximal. Quando se considerou os tumores localizados no cólon proximal comparando homens e mulheres, a proteína p53 era negativa em $37 \%$ (4/11) e $26.7 \%$ (4/15) respectivamente.

Existem evidências de que a expressão da proteína p53 possa sofrer interferência segundo a etnia considerada ${ }^{21}$. Estudos comparando a expressão da proteína mutante segundo a etnia do doente demonstraram que indivíduos da raça branca apresentam maior incidência de mutações da proteína p53 de tumores no CD (63\%), quando comparados aos do CP $(38 \%)$, fato não observado nos indivíduos da raça negra ${ }^{21}$. No Brasil, país com grande miscigenação racial, seria importante a realização de estudos avaliando a expressão da proteína p53 em relação à localização da neoplasia, com objetivo de comparar os resultados com os de outros países, contudo, estas pesquisas ainda não foram realizadas. Na presente casuística 90\% dos enfermos eram da raça branca, 5\% negra, e 5\% amarela o que prejudicava análise estatística fidedigna.

De modo diferente à literatura, onde não se identifica diferença significante na expressão da proteína p53 segundo a faixa etária, encontrou-se tendência a mutações da proteína nos enfermos com idade menos avançada ${ }^{18}$. Talvez este fato possa ser explicado pelo número de doentes existentes em cada grupo, ao se constatar que dos enfermos com tumores localizados no CD, com 70 anos ou menos, $81 \%$ (47/58) apresentavam mutações da proteína $\mathrm{p} 53$, enquanto nos doentes com mais de 70 anos e tumores localizados no CD, $75 \%$ (12/16) apresentavam mutação.

Até o momento existem dúvidas na relação entre mutações da proteína p53 e grau histológico da neoplasia ${ }^{18}$. Na presente casuística observou-se que $100 \%$ (4/4) dos enfermos com tumores pouco diferenciados, 80,9\% (51/63) moderadamente e 66,6\% (22/33) bem diferenciadas apresentavam mutações da proteína p53 ( $\mathrm{p}=0,001)$. Talvez, os resultados discrepantes encontrados quando comparados com os da literatura, possam ser explicados pela falta de uniformidade na correta definição do grau histológico, bem como ao local escolhido para realizar a leitura imunoistoquímica. No presente estudo, com objetivo de minimizar tais variações, a leitura foi realizada sempre no local coincidente com o grau histológico definido pela técnica da hematoxilina-eosina.

Verificou-se maior expressão da proteína p53 independentemente do tipo histológico considerado (adenocarcinoma produtores e não produtores de muco). Contudo, 30,7\% (8/26) dos tumores produtores de muco, localiza- 
dos no CP, não apresentavam mutações da proteína, enquanto a mutação ocorria em somente $14,8 \%$ (11/74) dos tumores do CD. Estes achados estão de acordo com a literatura que mostra tendência dos tumores produtores de muco do CP não apresentarem mutações na proteína p537.

Ao considerar as dimensões da neoplasia, verificouse que tumores com maiores dimensões não apresentavam tendência a mutações da proteína p53 $(\mathrm{p}=0,08)$. Todavia, neoplasias com maior profundidade de invasão da parede intestinal $\left(\mathrm{T}_{3-4}\right)$ apresentavam maiores índices de mutações do que àquelas com menor grau de invasão $(\mathrm{p}=0,001)$. Verificouse que enfermos com invasão linfonodal também possuíam maior tendência a mutações da proteína $(\mathrm{p}=0,001)$. De modo semelhante, a invasão angiolinfática também se relacionava à maior tendência de mutações $(\mathrm{p}=0,02)$. Corroborando estas evidências, doentes com estádios mais avançados da classificação TNM (III e IV) apresentavam maior relação com a expressão tecidual da proteína mutante $(\mathrm{p}=0,001)$.

Estudos vêm demonstrando menor resposta à terapia adjuvante nos doentes com tumores onde existem mutações na proteína p53 ${ }^{18,20}$. Este fato pode ser explicado pela necessidade de proteína funcionante para induzir a apoptose celular nas células danificadas pela radioterapia e quimioterapia ${ }^{30}$. Adell et al. verificaram que tumores localizados no reto, com mutações da proteína p53, cursavam com maiores índices de recidiva após a radioterapia neoadjuvante ${ }^{32}$. Takeda et al., por meio da dosagem sérica de anticorpos antip53 mutante, constataram, em pacientes com CCR, que a presença de mutações encontrava-se relacionada a menor resposta terapêutica à quimioterapia, podendo servir como importante marcador utilizado na seleção de terapia adjuvante ${ }^{33}$.

A importância da localização da neoplasia no cólon pode ser bem avaliada ao verificar-se que ocorrem diferentes respostas à terapia adjuvante quando se comparam tumores com mutações da p53 localizados no $\mathrm{CP}$ e $\mathrm{CD}^{7,20,21,23}$. Demonstrou-se que tumores localizados no reto apresentam correlação significante entre mutações da proteína p53 e menor intervalo livre de doença, principalmente quando se considera o intervalo livre de recidivas loco-regionais ${ }^{34}$. Cabe destacar que mutação da proteína p53 não pode ser considerada como variável relacionada ao prognóstico em todos os doentes com CCR, uma vez que nos tumores do CP não se encontrou correlação entre mutações da proteína e prognóstico desfavorável ${ }^{34}$. Mais importante ainda são os resultados de recente estudo que revisou cinco ensaios de fase III onde se empregou quimioterapia com 5-FU em doentes com tumores nos estádios II e III ${ }^{35}$. Neste estudo, portadores de neoplasias com IMS apresentavam melhores índices de sobrevida no grupo que não recebeu quimioterapia com 5-FU em contraste ao grupo que recebeu quimioterapia. Os benefícios, portanto, foram restritos aos doentes onde não existia IMS ${ }^{35}$. De modo surpreendente, os resultados desse estudo, indicaram que a adjuvância com 5-FU poderia potencialmente diminuir o intervalo livre de doença entre os doentes com tumores associados a IMS ${ }^{27}$. Cabe lembrar que tumores com IMS ocorrem com maior freqüência no CP.

Depreende-se do exposto que a presença de mutações na proteína p53 apresenta valor prognóstico diferente quando se consideram tumores localizados antes e após a flexura esplênica. ${ }^{20,36}$. Estas evidências sugerem que a resposta ao tratamento adjuvante possa estar relacionada a capacidade de indução da apoptose celular mediada pela presença da proteína normal, demonstrando diferentes respostas clínicas em relação a sobrevida e intervalo livre de doença. Assim sendo, o emprego de tratamento adjuvante deve considerar as diferentes vias de carcinogênese existentes entre tumores localizados nos $\mathrm{CP}$ e $\mathrm{CD}^{37}$. Como as mutações da proteína p53 ocorrem de forma distinta no intestino grosso, a localização da neoplasia no intestino também deveria ser considerada ao se programar a terapia adjuvante.

O paradigma que na realidade existam dois cólons e dois tipos de câncer reforçam a importância da correlação entre aspectos embriológicos, fisiológicos, genéticos e moleculares nos mecanismos de carcinogênese colorretal. Os resultados do presente estudo confirmam as diferenças na expressão da proteína p53 ao se comparar tumores localizados no cólon proximal e distal e diante aliado as evidências descritas na literatura indicam que a localização do tumor em relação à flexura esplênica deverá ser considerada para seleção mais criteriosa dos candidatos à terapia adjuvante. De outra forma estaremos propondo tratamentos complementares semelhantes para tumores com carcinogênese distintas e conseqüentemente com diferentes respostas terapêuticas.

\begin{abstract}
Background: The objective of this study was to investigate if there are any differences in tissue expression of p53 protein according to tumor location in colorectal cancer patients. Method: One hundred colorectal adenocarcinoma patients (54 women) of mean age 59.8 years were studied. Expression of p53 protein was analyzed through immunohistochemistry, using anti-p53 monoclonal antibodies and the streptavidin-biotin-peroxidase technique. Correlations between tissue expression of 53 protein and the following variables were investigated: gender, age, histological grade, histological type, tumor size, TNM staging, depth of intestinal wall invasion, lymph node involvement, angiolymphatic invasion, and proximal or distal tumor location in relation to the splenic flexure. For statistical evaluation of the relationship between 53 protein expression and these variables, the chi-squared test was used, with the significance level set at $5 \%(p<0.05)$. Results: There was positivity for $p 53$ protein in $75 \%$ of the cases. Among the different variables considered, a greater tendency towards expression of the mutant protein was found in relation to age $(p=0.001)$, a histological grade $(p=0.001)$, a histological type $(p=0.001)$, advanced TNM staging $(p=0.001)$, deeper depth of colon wall invasion $(p=0.001)$, lymph node involvement ( $p=0.001)$, angiolymphatic invasion $(p=0.02)$ and distal location to the splenic flexure $(p=0.001)$. However, there was no relationship with gender $(p=0.49)$ or tumor size $(p=0.08)$. Conclusion: The results from this study allow the conclusion that the expression of mutant 53 protein occurs more frequently in tumors located distally to the splenic flexure.
\end{abstract}

Key words: Colonic neoplasms; Tumor markers, biological; Tumor suppressor protein p53; Genes, p53; Immunohistochemistry. 


\section{REFERÊNCIAS}

1. Brasil. Ministério da Saúde. Secretaria de Atenção à Saúde. Instituto Nacional de Câncer. Coordenação de Prevenção e Vigilância de Câncer. Estimativas 2008: Incidência de Câncer no Brasil. Rio de Janeiro: INCA; 2007. 94p.

2. Boring CC, Squires TS, Tong T. Cancer statistics, 1993. CA Cancer J Clin.1993;43(1):7-26.

3. Parker SL, Tong T, Bolden S, Wingo PA. Cancer statistics, 1996. CA Cancer J Clin. 1996;46(1):5-27.

4. Obrand DI, Gordon PH. Continued change in the distribution of colorectal carcinoma. Br J Surg. 1998;85(2):246-8.

5. Levi F, Randimbison L, La Vecchia C. Trends in subsite distribution of colorectal cancers and polyps from the Vaud Cancer Registry. Cancer. 1993;72(1):46-50.

6. Jass JR. Subsite distribution and incidence of colorectal cancer in New Zealand 1974-1983. Dis Colon Rectum. 1991;34(1):569.

7. Gervaz P, Bouzourene H, Cerottini JP, Chaubert P, Benhattar J, Secic M, et al. Dukes B colorectal cancer: distinct genetic categories and clinical outcome based on proximal or distal tumor location. Dis Colon Rectum. 2001;44(3):364-72; discussion 3723.

8. Buffill JA. Colorectal cancer: evidence for distinct genetic categories based on proximal or distal tumor location. Ann Intern Med. 1990;113(10):779-88.

9. Distler P, Holt PR. Are right and left-sided neoplasms distinct tumors? Dig Dis. 1997;15(4-5):302-11.

10. Pocard M, Salmon RJ, Muleris M, Remvikos Y, Bara J, Dutrillaux B, Poupon MF. [Two colon-two cancers? Proximal or distal adenocarcinoma: arguments for a different carcinogenesis]. Bull Cancer. 1995;82(1):10-21.

11. Glebov OK, Rodriguez LM, Nakahara K, Jenkins J, Cliatt J, Humbyrd CJ, et al. Distinguishing right from left colon by the pattern of gene expression. Cancer Epidemiol Biomarkers Prev. 2003;12(8):755-62.

12. Konishi K, Fujii T, Boku N, Kato S, Koba I, Ohtsu A, et al. Clinicopathological differences between colonic and rectal carcinomas: are they based on the same mechanism of carcinogenesis? Gut.1999;45(6):818-21.

13. Volgelstein B, Fearon ER, Hamilton SR, Kern SE, Preisinger AC, Leppert M, et al. Genetic alterations during colorectal tumor development. N Engl J Med. 1988;319(9):525-32.

14. Fearon ER, Vogelstein B. A genetic model for colorectal tumorigenesis. Cell. 1990;61(5):759-67.

15. Bedenne L, Faivre J, Boutron MC, Piard F, Cauvin JM, Hillon P. Adenoma-carcinoma sequence or "de novo" carcinogenesis? A study of adenomatous remnants in a population-based series of large bowel cancers. Cancer. 1992;69(4):883-8.

16. Kim H, Jen J, Vogelstein B, Hamilton SR. Clinical and pathological characteristics of sporadic colorectal carcinomas with DNA replication errors in microsatellite sequences. Am J Pathol. 1994;145(1):148-56.

17. Adrover E, Maestro ML, Sanz-Casla MT, del Barco V, Cerdán J, Fernández C, Balibrea JL. Expression of high p53 levels in colorectal cancer: a favourable prognosis factor. Br J Cancer. 1999;81(1):122-6.

18. Soong R, Powell B, Elsaleh H, Gnanasampanthan G, Smith DR, Goh HS, et al. Prognostic significance of TP53 gene mutation in 995 cases of colorectal carcinoma. Influence of tumor site, stage, adjuvant chemotherapy and type mutation. Eur J Cancer. 2000;36(16):2053-60.

19. Ribeiro Júnior U, Alves VA, Souza PMB, Ribeiro AV, Rawet V, Nonogaki S, et al. Correlação das proteínas p53 e KI-67 com o prognóstico de pacientes com adenocarcinoma de reto distal. Rev Bras Coloproct. 2000;20(4):248-56.

20. Diez M, Medrano M, Mugüerza JM, Ramos P, Hernandez P, Villeta $R$, et al. Influence of tumor localization on the prognostic value of $\mathrm{p} 53$ protein in colorectal adenocarcinomas. Anticancer Res. 2000;20(5C):3907-12.

21. Manne U, Weiss HL, Myers RB, Danner OK, Moron C, Srivastava S, Grizzle WE. Nuclear accumulation of p53 in colorectal adenocarcinoma: prognostic importance differs with race and location of the tumor. Cancer. 1998;83(12):2456-67.

22. Watatani M, Yoshida T, Kuroda K, Ieda S, Yasutomi M. Allelic loss of chromosome $17 \mathrm{p}$, mutation of the p53 gene, and microsatellite instability in right and left colorectal cancer. Cancer. 1996;77(8 Suppl):1688-93.

23. Sun XF, Carstensen JM, Zhang H, Arbman G, Nordenskjöld B. Prognostic significance of p53 nuclear and cytoplasmic overexpression in right and left colorectal adenocarcinoma. Eur J Cancer. 1996;32A(11):1963-7.

24. Iacopetta B. Are there two sides to colorectal cancer? Int J Cancer. 2002;101(5):403-8.

25. Beart RW, Melton LJ 3rd, Maruta M, Dockerty MB, Frydenberg HB, O'Fallon WM. Trends in right and left-sided colon cancer. Dis Colon Rectum. 1983;26(6):393-8.

26. Breivik J, Lothe RA, Meling GI, Rognum TO, Børresen-Dale Al, Gaudernack G. Different genetic pathways to proximal and distal colorectal cancer influenced by sex-related factors. Int $\mathbf{J}$ Cancer.1997;74(6):664-9.

27. Giovannucci E, Colditz GA, Stampfer MJ. A meta-analysis of cholecystectomy and risk of colorectal cancer. Gastroenterology.1993;105(1):130-41.

28. Gervaz P, Bucher P, Morel P. Two colons-two cancers: paradigm shift and clinical implications. J Surg Oncol. 2004;88(4):261-6.

29. Pinho MSL, Rossi BM. As proteínas envolvidas na carcinogênese colorretal. Rev Bras Coloproct. 1998:18(4):278-82.

30. Pinho MSL. Proteína p53: algum valor clínico ou apenas pesquisa? Uma revisão da literatura. Rev Bras Coloproct. 2000;20(4):258-60.

31. Kahlenberg MS, Stoler DL, Rodriguez-Bigas MA, Weber TK, Driscoll DL, Anderson GR, Petrelli NJ. p53 tumor suppressor gene mutations predict decreased survival of patients with sporadic colorectal carcinoma. Cancer. 2000;88(8):1814-9.

32. Adell G, Sun XF, Stål O, Klintenberg C, Sjödahl R, Nordenskjöld B. p53 status: an indicator for the effect of preoperative radiotherapy of rectal cancer. Radiother Oncol. 1999;51(2):16974.

33. Takeda A, Nakajima K, Shimada H, Imaseki H, Takayama W, Hayashi $\mathrm{H}$, et al. Clinical significance of serum p53 antibody detection on chemosensitivity assay in human colorectal cancer. J Surg Oncol. 1999;71(2):112-6.

34. Kapiteijn E, Liefers GJ, Los LC, Kranenbarg EK, Hermans J, Tollenaar RA, et al. Mechanisms of oncogenesis in colon versus rectal cancer. J Pathol. 2001;195(2):171-8.

35. Ribic CM, Sargent DJ, Moore MJ, Thibodeau SN, French AJ, Goldberg RM, et al. Tumor microsatellite-instability status as a predictor benefit from fluorouracil-based adjuvant chemotherapy for colon cancer. N Engl J Med. 2003;349(3):247-57.

36. Hamelin R, Laurent-Puig P, Olschwang S, Jego N, Asselain $\mathrm{B}$, Remvikos Y, et al. Association of p53 mutations with short survival in colorectal cancer. Gastroenterology. 1994;106(1):42-8.

37. Okubo R, Masuda H, Nemoto N. p53 mutation found to be a significant prognostic indicator in distal colorectal cancer. Onco Rep. 2001;8(3):509-14. 
Como citar este artigo:

Martinez CA, Priolli DG, Cardinalli IA, Pereira JA, Portes AV, Margarido NF. Influência da localização do tumor na expressão tecidual da proteína p53 em doentes com câncer colorretal. Estudo de 100 casos. Rev Col Bras Cir. [periódico na Internet] 2008; 35(4). Disponível em URL: http://www.scielo.br/rcbc
Endereço para correspondência:

Carlos Augusto Real Martinez

Rua Rui Barbosa, 255 apto. 32.

09190-370 - Santo André - SP

Tel: (11) 4438-9203 / (11) 4436-0453

E-mail: caomartinez@uol.com.br 